\title{
A second Middle Eastern kindred with autosomal recessive non-syndromic hearing loss segregates DFNB9
}

\author{
Suzanne M Leal ${ }^{1,2}$, Fazil A paydin ${ }^{3}$, Carol Barnwell ${ }^{4}$, M etin Iber $^{3}$, Tolga Kandogan ${ }^{3}$, \\ M arkus Pfister ${ }^{2}$, U we Braendle ${ }^{2}$, O rhan Cura ${ }^{3}, \mathrm{M}$ arvin Schwalb ${ }^{4}, \mathrm{H}$ ans-Peter Zenner ${ }^{2}$ \\ and Emilia Vitale \\ ${ }^{1} \mathrm{~L}$ aboratory of Statistical G enetics, Rockefeller U niversity, N ew York, USA \\ ${ }^{2} \mathrm{D}$ epartment of $\mathrm{O}$ tolaryngology, U niversity of Tübingen, $\mathrm{G}$ ermany \\ ${ }^{3} \mathrm{D}$ epartment of O tolaryngology, E ge U niversity M edical School, I zmir, Turkey \\ ${ }^{4} \mathrm{D}$ epartment of M icrobiology and M olecular G enetics, N ew Jersey M edical School, N ewark, USA
}

\begin{abstract}
A second kindred has been identified which supports the previously reported location of DFNB9. Linkage has been established to markers closely linked to DFNB9 which is located on 2p22-p23. The hearing impaired individuals in this highly consanguineous kindred from Eastern Turkey have prelingual profound hearing loss which affects all frequencies. A genetic map of the 2p22-p23 region where DFNB9 resides was generated using marker genotypes available from the CEPH database. All markers were placed on this genetic map using a likelihood ratio criterion of 1000:1. This map suggests that the region for DFNB9 is less than $1.08 \mathrm{cM}, 95 \%$ confidence interval $(0-2.59 \mathrm{cM})$.
\end{abstract}

Keywords: Autosomal recessive non-syndromic hearing loss; sensorineural hearing loss; DFNB9

\section{Introduction}

Thus far, 16 autosomal recessive hearing loss genes (DFNB) have been localized, of which two have been isolated: the unconventional myosin VIla gene for DFNB $2^{1,2}$ and Connexin $26^{3}$ for DFNB 1.

The hearing impaired individuals from kindreds which segregate known DFNB loci manifest prelingual profound hearing loss, with the exception of DNFB 8 where hearing impaired individuals present with postlingual progressive hearing loss. Linkage has been

Correspondence: Dr Suzanne M L eal, Laboratory of Statistical G enetics, 1230 Y ork, A venue, B ox 192, N ew Y ork, NY 10021-6399. Tel: 1 (212) 327 7992; Fax: 1 (212) 327 7996; E-mail: lealsm@rockvax.rockefeller.edu

R eceived 25 A ugust 1997; revised 12 January 1998; accepted 13 January 1998 reported for more than one family for the majority of the DFNB loci (DFNB 1-4, DFNB 7/11, DFNB 8/10). ${ }^{4}$

$A$ second family with autosomal recessive neurosensory hearing loss that segregates DFNB9 is presented here. DFNB9 was previously mapped to $2 p 22-23$ in a consanguineous family from Lebanon. ${ }^{5}$ Linkage was established to markers closely linked to DFNB 9 in this highly consanguineous kindred from E astern Turkey.

\section{Material and Methods}

\section{Auditory Tests}

Informed consent was obtained from all study participants and from the parents of under-aged study participants. Puretone audiometry with air and bone conduction at 250, 500, 
$1000,2000,4000$, and $8000 \mathrm{~Hz}$ was performed on all living pedigree members, except for individual VI.3 for whom auditory brain response (A BR ) was performed due to her age of less than one year. In addition all individuals received an otoscopic examination.

\section{Genotyping}

Genomic DNA was extracted from $10 \mathrm{ml}$ of blood using the QIA amp System B lood K its from Q U IA G E N. A mplification of the microsatellite markers was performed using standard methods previously described. ${ }^{6}$ The primer sequences of the Genethon and CHLC markers: D2S144; D2S14; D 2S158; D 2S170; D 2S171; D2S174; D 2S305; D 2S310; D 2S365; D 2S375; D 2S405; D 2S1325; D 2S2144; D 2S2263; and D 2S2303 have been previously reported.,8

\section{Linkage Analysis}

Two-point lod scores were calculated using MLINK of the L INK A G E 5.1 computer program package. ${ }^{9}$ The analysis was done under an autosomal recessive mode of inheritance, where the disease phenotype is fully penetrant with no phenocopies. The recombination fraction was assumed to be equal for males and females. The disease frequency was set to 0.0001 . Since the disease frequency is unknown, linkage analysis was also carried out varying the disease frequency between 0.01 and 0.00001 in order to evaluate the effect of changing the allele frequencies on the lod score. The allele frequencies for the markers were assumed to be equal, since the true allele frequency for this population is unknown. To avoid obtaining a false positive result due to using a low allele frequency for a common allele, the linkage analysis was also carried out with the allele frequency doubled for the allele that segregates with the disease allele.

Since all the markers analyzed had not previously been placed on a single genetic map, a map was generated using publicly available genotype data from the CEPH database. ${ }^{10}$ M ultiM ap and CRI-MA P were used to place the markers on a genetic map using a likelihood criterion of 1000:1. ${ }^{11,12}$ The confidence interval for D F N B 9 locus was calculated using the variance-covariance matrix, which was given by CILINK. ${ }^{9}$

\section{Results and Discussion}

Figure 1 illustrates a genetic map of the 2p22-p23 region where DFNB 9 resides. A sterisks denote those markers for which there were no recombination events in the CEPH data. The relative order of these markers is unknown. Those markers which belong to the same linkage group but which could not be placed uniquely on the genetic map with a likelihood ratio of 1000:1 are mapped to intervals and are shown next to the map. It was previously reported that DFNB9 lies between D 2 S2303 and D 2S174. ${ }^{5}$ This genetic map suggests that this region is $1.08 \mathrm{cM}, 95 \%$ confidence interval $(0$, $2.59 \mathrm{cM})$.

Figure 2 shows a drawing of Turkey-21, the kindred segregating DFNB 9. The hearing impaired individuals within this kindred have profound hearing loss affect-

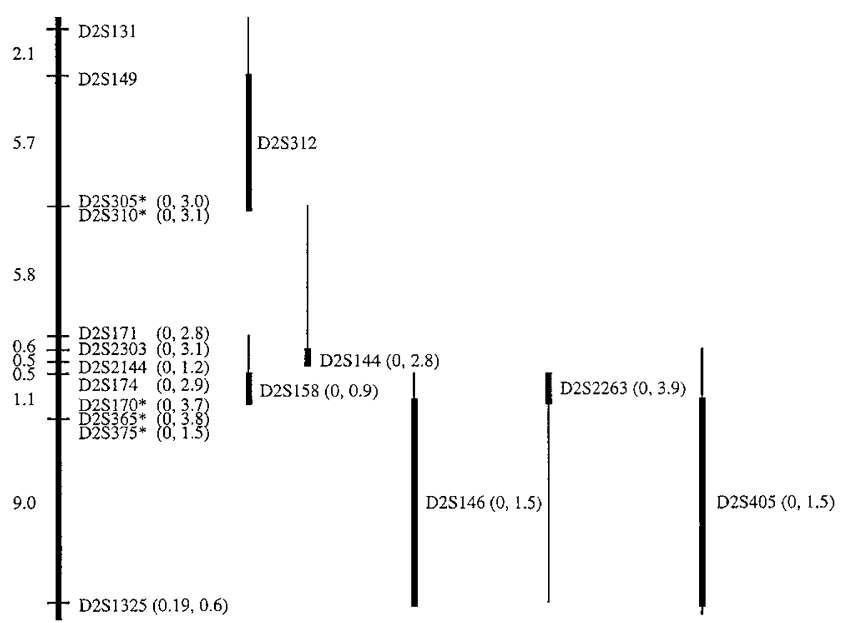

Figure 1 A genetic map of markers within the region of DFNB 9. The map distances are given in Kosambi centimorgans. Those markers that could not be localized to a single map position with a likelihood ratio criterion of 1000:1 are placed in intervals and are shown on the side of the map. The bold portion of the bar denotes the most likely position of the marker. The results of the linkage analysis for Turkey 21 appear in parentheses alongside each marker. The second number in the parentheses is the maximum lod score and the first number is the recombination fraction at which it occurred.

ing all frequencies with onset before the second year of life. This kindred supports the previously identified location of DFNB 9. However, this kindred did not aid in the reduction of the genetic region for DNFB 9; the disease haplotype for this kindred is over $17.5 \mathrm{cM}$. The results of the linkage analysis for all markers tested are shown in Figure 1. The maximum lod scores and the recombination fraction at which each occurred are shown in parentheses next to each marker tested. A maximum lod score of 3.9 was obtained at recombination fraction 0.0 for marker D2S2263. When the allele frequency was doubled for the marker allele which segregated with the disease allele, the lod scores remained significant for markers D2S2663, D 2S365, and D 2S170. The results also stayed significant for these three marker loci when the disease allele frequency was varied between 0.01 and 0.00001 .

Two additional consanguineous autosomal recessive NSH L kindreds from Western Turkey were genotyped for markers closely linked to DFNB9. Linkage was excluded to the genetic region for DFNB 9 for each of these kindreds (data not shown).

Turkey-21 is the second kindred to be reported which segregates DFNB9. The members of this kindred originally come from E astern Turkey, a region which is 

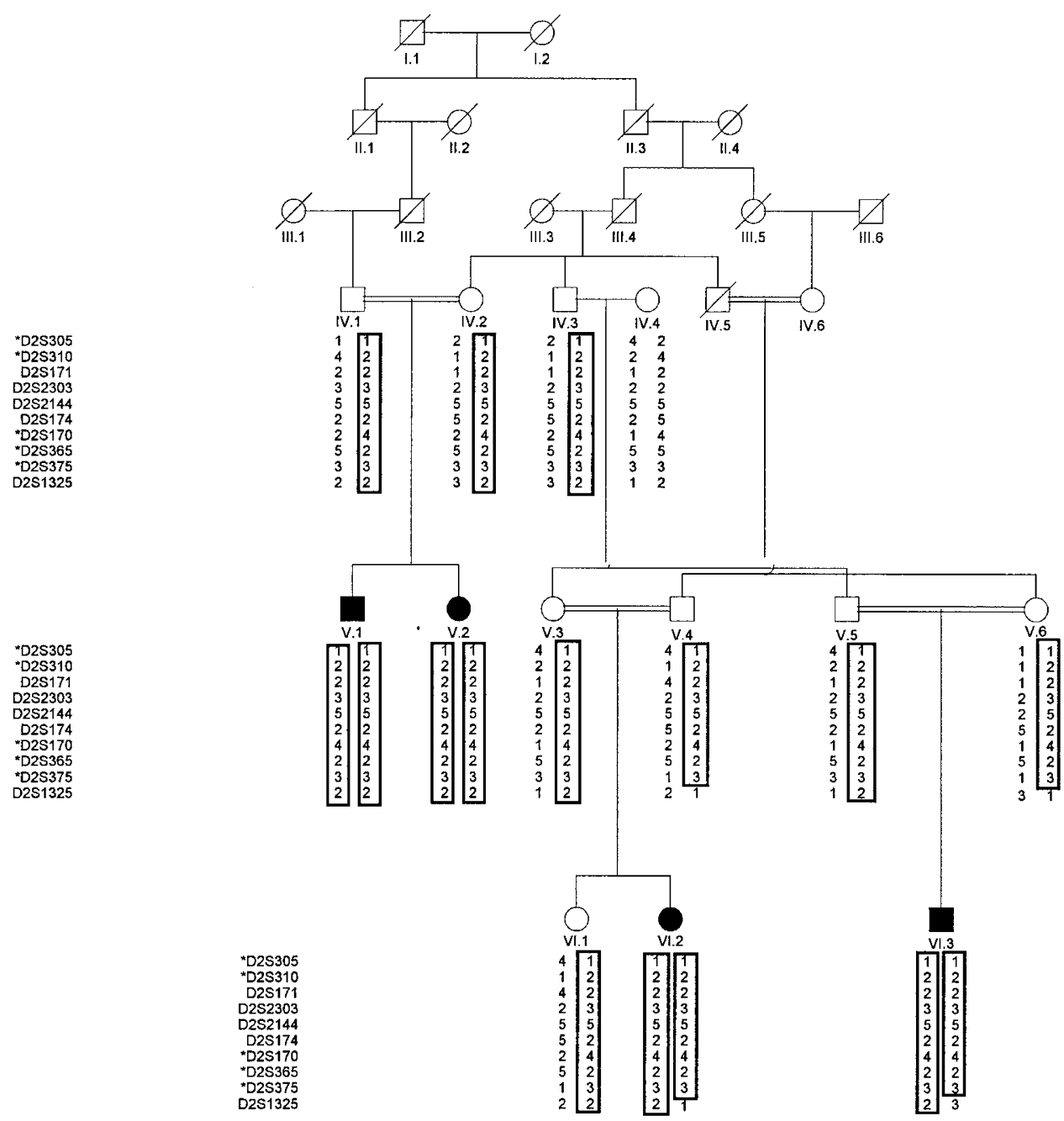

Figure 2 The pedigree drawing for Turkey-21 showing the segregation of linked loci. The boxed haplotype is associated with D F N B 9. The filled-in symbols represent hearing impaired family members.

not geographically distant from Northern Lebanon, where the members of the first kindred reported to segregate DFNB 9 reside. Only through additional study will the prevalence of DFNB 9 be elucidated. A broader examination will show whether or not its occurrence is limited to this $\mathrm{M}$ iddle $\mathrm{E}$ astern geographic region.

\section{Acknowledgements}

This work was supported by the Deutsche Forschungsgemeinschaft (Klifo Hörforschung; Z el 49/6-1), the ScheringPlough Corporation and NIH grant HG00008.

\section{References}

1 Liu X Z, Walsh J, M buru P et al: M utations in the myosin VIIA gene cause non-syndromic recessive deafness. $\mathrm{N}$ at G enet 1997; 16: 188-190.

2 Weil D, Kusel P, Blanchard et al: The autosomal recessive isolated deafness, DFNB 2, and the U sher $1 B$ syndrome are allelic defects of the myosin-VIIA gene. Nat Genet 1997; 16: 191-193.

3 Kelsell DP, Dunlop J, Stevens HP et al: Connexin 26 mutations in hereditary non-syndromic sensorineural deafness. Nature 1997; 387: 80-83.

4 Van Camp G, Willems PJ, Smith RJH: Nonsyndromic hearing impairment: unparalleled heterogeneity. Am J H um G enet 1997; 60: 758-764.

5 Chaib $\mathrm{H}$, Place $\mathrm{C}$, Salem $\mathrm{N}$ et al: A gene responsible for a sensorineural nonsyndromic recessive deafness maps to chromosome 2p22-23. H um M ol G enet 1996; 5: 155-158. 
6 Hughes AE: O ptimization of microsatellite analysis for genetic mapping. G enomics 1993; 15: 433-434.

7 D ib C, Fauré, Fizames C et al: Comprehensive genetic map of the human genome based on 5,264 microsatellites. Nature 1994; 380: 152-154.

8 Murray J C, Buetow $\mathrm{KH}$ et al: A comprehensive human linkage map with centimorgan density. Science 1994; 265: 2049-2054.

9 L athrop GM, Lalouel J M, Julier C, Ott J: Strategies for multilocus linkage analysis in humans. Proc $\mathrm{N}$ atl $\mathrm{A}$ cad $\mathrm{Sci}$ USA 1984; 81: 3443-3446.
10 D ausset J, Cann $H$, C ohen D, Lathrop $M$, L alouel J-M, White R: Centre d'Etude du Polymorphise Humain $(\mathrm{CEPH})$ : Collaborative genetic mapping of the human genome. G enomics 1990; 6: 575-577.

11 Matise T, Perlin M, Chakravarti A : A utomated construction of genetic linkage maps using an expert system (MultiM ap): a human genome linkage map. $\mathrm{N}$ at $\mathrm{G}$ enet 1994; 6: 384-390.

12 Lander ES, G reen P: Construction of multi-locus genetic linkage maps in humans. P roc $N$ atl A cad Sci USA 1987; 84: 2363-2367. 